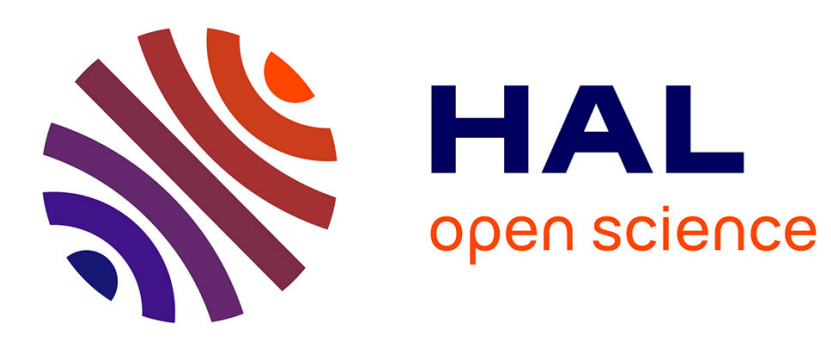

\title{
Multifrequency Wilkinson power divider using microstrip nonuniform transmission lines
}

M. Khalaj-Amirhosseini, M. Moghavvemi, Hossein Ameri Mahabadi

\section{To cite this version:}

M. Khalaj-Amirhosseini, M. Moghavvemi, Hossein Ameri Mahabadi. Multifrequency Wilkinson power divider using microstrip nonuniform transmission lines. International Journal of RF and Microwave Computer Aided Engineering, 2011, 21 (3), pp.295-299. hal-00722716

\section{HAL Id: hal-00722716 https://hal.science/hal-00722716}

Submitted on 3 Aug 2012

HAL is a multi-disciplinary open access archive for the deposit and dissemination of scientific research documents, whether they are published or not. The documents may come from teaching and research institutions in France or abroad, or from public or private research centers.
L'archive ouverte pluridisciplinaire $\mathbf{H A L}$, est destinée au dépôt et à la diffusion de documents scientifiques de niveau recherche, publiés ou non, émanant des établissements d'enseignement et de recherche français ou étrangers, des laboratoires publics ou privés. 


\title{
Multifrequency Wilkinson Power Divider Using Microstrip Nonuniform Transmission Lines
}

\author{
Mohammad Khalaj-Amirhosseini, ${ }^{1}$ Mahmoud Moghavvemi, ${ }^{2}$ Hossein Ameri ${ }^{2}$ \\ ${ }^{1}$ College of Electrical Engineering, Iran University of Science and Technology (IUST), Tehran, Iran \\ 2 Department of Electrical Engineering, University of Malaya (UM), Kuala Lumpur, Malaysia
}

Received 13 September 2010; accepted 1 December 2010

\begin{abstract}
A new idea is proposed to modify the conventional Wilkinson power dividers to operate at two or several desired frequencies. The proposed structure contains two Microstrip Nonuniform Transmission Lines (MNTLs) instead of two uniform ones with nearly the same length at the minimum frequency. The strip width of MNTLs is considered variable and is written as a truncated Fourier series. Three nonuniform power dividers are designed and one of them operating at frequencies $1.0,2.8$, and $4.5 \mathrm{GHz}$ is fabricated and measured. The measured results of the fabricated diplexer have a good agreement with the theoretical results. (c) 2011 Wiley Periodicals, Inc. Int J RF and Microwave CAE 21:295-299, 2011.
\end{abstract}

Keywords: Wilkinson power divider; multifrequency power divider; microstrip nonuniform transmission lines

\section{INTRODUCTION}

Power dividers are one of the important components in microwave circuits to divide a power to at least two channels, or combine the powers in a channel if they are passive. The commonly used microstrip power dividers are Branch-Line [1] and Wilkinson [1,2] types. The outputs of the former one are in-quadrature and of the later one are in-phase. One of limitations of these power dividers is that they operate properly only at a fundamental frequency and its odd harmonics. Therefore, they are not suitable for the recently increasing number of dual and multiband applications. Some efforts have been done to modify the conventional Wilkinson power dividers to make them operate at two or several desired frequencies [3-7]. The main proposed ideas for multiband Wilkinson power dividers are using a multistage structure consisting of several cascaded power dividers [3-6] and using composite right/left-handed transmission line (CRLH) [7]. The main disadvantage of multistage and CRLH power dividers is their large length and obligation to use lumped elements, respectively. On the other hand, one of the concerns of researchers is to compact the microwave components. In this article, a new idea is proposed to modify the conventional Wilkinson power dividers to operate at more than

Correspondence to: M. Khalaj-Amirhosseini; e-mail: khalaja@ iust.ac.ir

DOI 10.1002/mmce.20517

Published online 30 March 2011 in Wiley Online Library (wileyonlinelibrary.com). one desired frequencies. The proposed structure contains two microstrip nonuniform transmission lines (MNTLs) instead of two uniform ones. The strip width of MNTLs is considered variable and is written as a truncated Fourier series. The optimum values of the coefficients of the Fourier series are obtained through an optimization approach. Finally, the performance of the proposed power divider is studied using three examples containing a fabricated one operating at three frequencies.

\section{NONUNIFORM POWER DIVIDER}

Figure 1a depicts a nonuniform Wilkinson power divider composed of two similar MNTLs of length $d$ along the $z$ axis that are terminated by source and load resistances $Z_{0}$ and are connected at their outputs by the internal resistance $R$. Also, Figure $1 \mathrm{~b}$ depicts the cross section of a typical MNTL whose relative electric permittivity and thickness are $\varepsilon_{\mathrm{r}}$ and $h$, respectively. The width of strip of MNTL is varying with $z$ as $w(z)$, also. MNTLs are designed in such a way so that the resulted power divider work at two or several arbitrary frequencies $f_{1}, f_{2}, f_{3}$, etc.

To analyze MNTLs, one can use quasi-TEM based methods such as cascading many short sections [8, 9], in which MNTLs are subdivided into many uniform, linear or exponentially electrically short sections and then the $A B C D$ matrix is obtained by multiplying the known $A B C D$ matrices of all short sections to each other.

After finding the $A B C D$ parameters and the input and output impedances of two MNTLs of the proposed power

(C) 2011 Wiley Periodicals, Inc. 


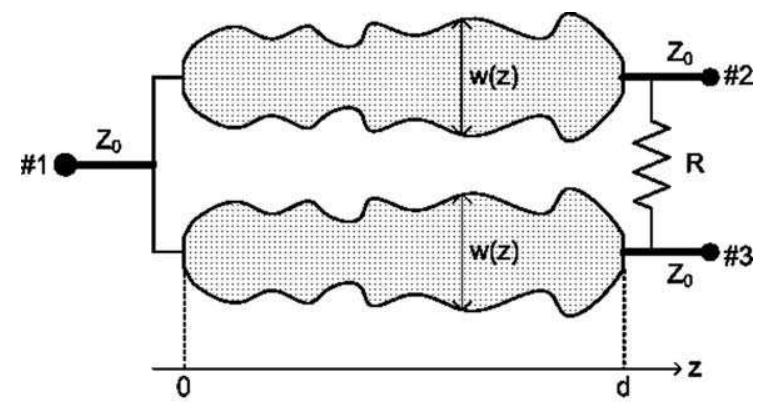

(a)

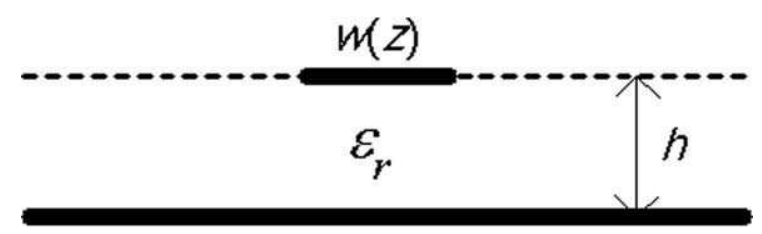

(b)

Figure 1 (a) Diplexer with two MNTLs (b) The cross section of an MNTL.

divider in two cases of even and odd modes, the $S$ parameters of the complete structure can be determined as follows:

$$
\begin{gathered}
S_{11}=\frac{Z_{\text {in }} / 2-Z_{0}}{Z_{\text {in }} / 2+Z_{0}} \\
S_{22}=S_{33}=\frac{1 Z_{\text {out }}^{e}-Z_{0}}{2}+\frac{1}{Z_{\text {out }}^{e}+Z_{0}} \frac{Z_{\text {out }}^{o}-Z_{0}}{2 Z_{\text {out }}^{o}+Z_{0}} \\
S_{23}=S_{32}=\frac{1}{2} \frac{Z_{\text {out }}^{e}-Z_{0}}{Z_{\text {out }}^{e}+Z_{0}}-\frac{1}{2} \frac{Z_{\text {out }}^{o}-Z_{0}}{Z_{\text {out }}^{o}+Z_{0}} \\
\left|S_{21}\right|=\left|S_{31}\right|=\sqrt{\left(1-\left|S_{11}\right|^{2}\right) / 2}
\end{gathered}
$$

where $Z_{\text {in }}$ is the input impedance of one of two branches in the even mode and also $Z_{\text {out }}^{e}$ and $Z_{\text {out }}^{o}$ are the output impedances of that branch in the even and odd modes, respectively. According to the equivalent circuits for even and odd modes, three impedances $Z_{i n}, Z_{\text {out }}^{e}$, and $Z_{\text {out }}^{o}$ can be derived simply using the obtained $A B C D$ parameters of each nonuniform transmission line, as follows

$$
\begin{gathered}
Z_{\text {in }}=\frac{A Z_{0}+B}{C Z_{0}+D} \\
Z_{\text {out }}^{e}=\frac{2 Z_{0} D+B}{2 Z_{0} C+A} \\
Z_{\text {out }}^{o}=\left(\left(\frac{B}{A}\right)^{-1}+\left(\frac{R}{2}\right)^{-1}\right)^{-1}=\frac{R B}{R A+2 B}
\end{gathered}
$$

TABLE II Optimum Values of the Length and Internal Resistance $\left(d_{0}\right.$ is the Length of Conventional Power Divider at $1 \mathrm{GHz}$ )

\begin{tabular}{lccc}
\hline$f[\mathrm{GHz}]$ & {$[1,2]$} & {$[1,3.5]$} & {$[1,2.8,4.5]$} \\
\hline$d[\mathrm{~mm}]$ & $61.49\left(1.1065 d_{0}\right)$ & $48.32\left(0.8696 d_{0}\right)$ & $55.70\left(1.0023 d_{0}\right)$ \\
$R[\Omega]$ & 86.21 & 102.33 & 99.84 \\
\hline
\end{tabular}

\section{SYNTHESIS OF POWER DIVIDER}

In this section, a general method is proposed to optimally design the proposed structure as a multifrequency power divider. First, we consider the following truncated Fourier series expansion for the normalized width function $w(z) / h$ of two MNTLs.

$$
\ln \left(\frac{w(z)}{h}\right)=\sum_{n=0}^{N} C_{n} \cos (\pi n z / d)
$$

The optimum values of the unknown coefficients $C_{\mathrm{n}}$ along with the length $d$ and internal resistance $R$ can be obtained through minimizing the following defined error function.

$$
\text { Error }=\sqrt{\frac{1}{9 N_{f}} \sum_{f}\left(\sum_{i=1}^{3} \sum_{j=1}^{3}|| S_{i j}(f)|-| S_{i j}^{\text {desired }}||^{2}\right)}
$$

where $N_{\mathrm{f}}$ is total number of optimized frequencies $f_{1}, f_{2}$, $f_{3}$, etc., and $S^{\text {desired }}$ is the desired scattering parameter matrix given by

$$
S^{\text {desired }}=\frac{1}{\sqrt{2}}\left[\begin{array}{ccc}
0 & -j & -j \\
-j & 0 & 0 \\
-j & 0 & 0
\end{array}\right]
$$

Moreover, the above-defined error function should be restricted by some electrical or physical constraints as follows:

$$
\left(\frac{w}{h}\right)_{\min } \leq \frac{w(z)}{h} \leq\left(\frac{w}{h}\right)_{\max }
$$

where $(w / h)_{\min }$ and $(w / h)_{\max }$ are the minimum and maximum available normalized width, respectively.

\begin{tabular}{|c|c|c|c|c|c|c|c|c|}
\hline$f[\mathrm{GHz}]$ & $C_{0}$ & $C_{1}$ & $C_{2}$ & $C_{3}$ & $C_{4}$ & $C_{5}$ & $C_{6}$ & $C_{7}$ \\
\hline$[1,2]$ & -0.0954 & -0.4099 & -0.0153 & 0.0793 & -1.0592 & -1.1107 & 0.6370 & 0.1807 \\
\hline$[1,3.5]$ & 0.5386 & 0.1972 & 0.1766 & -0.0644 & 0.1805 & 0.0082 & 0.1252 & -0.4028 \\
\hline$[1,2.8,4.5]$ & 0.6268 & -0.0045 & 0.1807 & 0.0307 & 0.2332 & 0.0801 & 0.5214 & -0.4902 \\
\hline
\end{tabular}

\section{EXAMPLES AND RESULTS}

In this section, three nonuniform power dividers are designed, and one of them is fabricated and measured, considering $Z_{0}=50 \Omega,(w / h)_{\min }=0.1$ and $(w / h)_{\max }=7$. The desired frequencies of designed power dividers are $[1,2] \mathrm{GHz},[1,3.5] \mathrm{GHz}$ and $[1,2.8,4.5] \mathrm{GHz}$. Tables I and II show the unknown coefficients, length of MNTLs and internal resistance for three designed power dividers. It is seen that the required length is smaller or at most

TABLE I Optimum Values of the Coefficients $C_{n}$ 


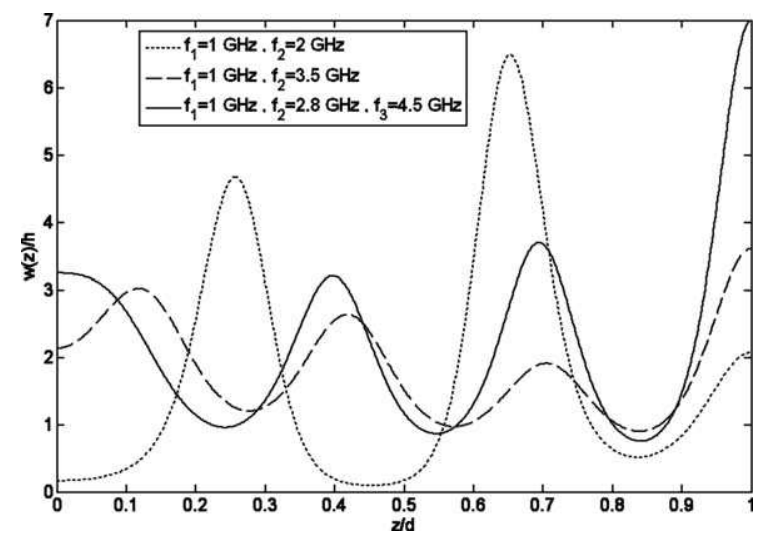

Figure 2 The normalized width function $w(z) / h$ for three designed power dividers.

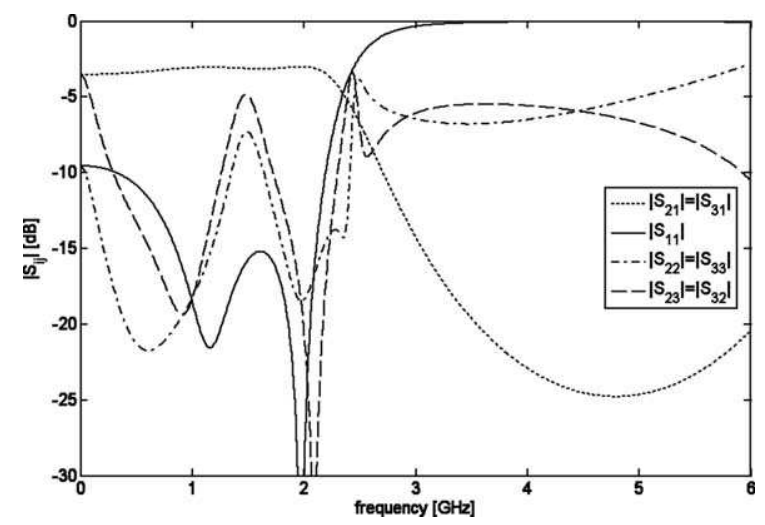

Figure 3 The amplitude of the scattering parameters of power divider of $[1,2] \mathrm{GHz}$.

$10 \%$ more than the length of a conventional Wilkinson power divider at fundamental frequency $1 \mathrm{GHz}$, i.e., $d_{0}=$ $55.57 \mathrm{~mm}$. Figure 2 depicts the normalized width function of MNTLs. Also, Figures 3 and 5 illustrate the amplitude of the scattering parameters of power dividers versus frequency. The deep nulls at desired frequencies are observable, and the minimum of the input and output return losses and the output isolation are 18,25 , and $35 \mathrm{~dB}$ for

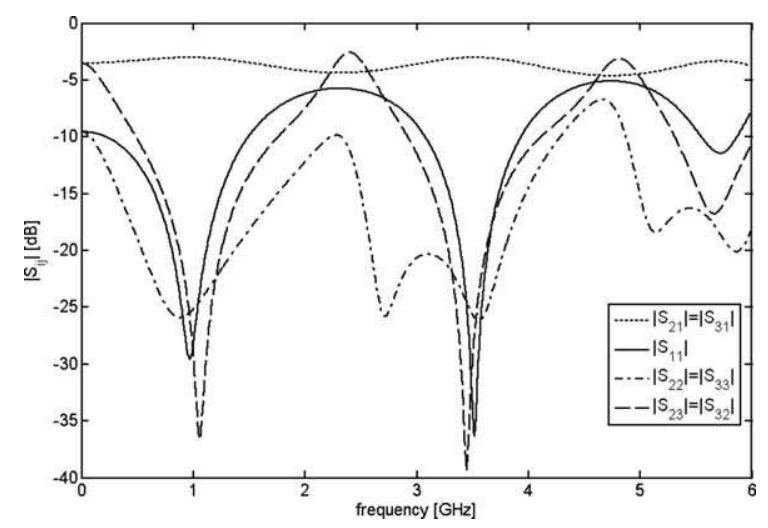

Figure 4 The amplitude of the scattering parameters of power divider of $[1,3.5] \mathrm{GHz}$.

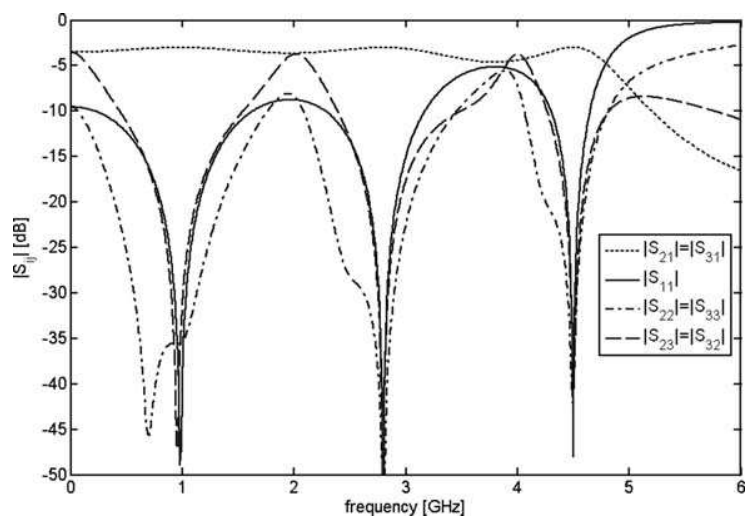

Figure 5 The amplitude of the scattering parameters of power divider of $[1,2.8,4.5] \mathrm{GHz}$.

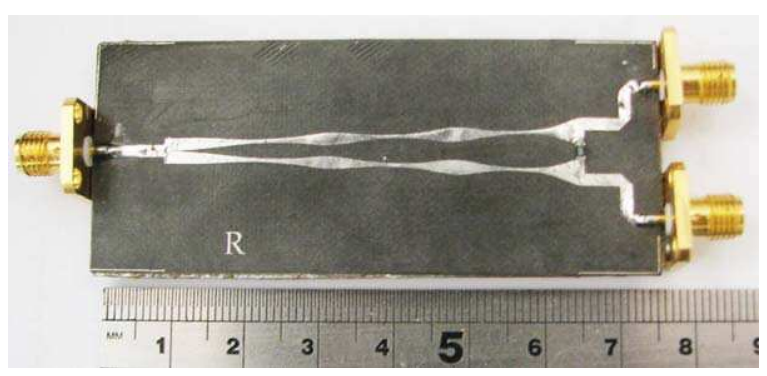

Figure 6 The photo of the fabricated power divider of [1, 2.8, 4.5] GHz. [Color figure can be viewed in the online issue, which is available at wileyonlinelibrary.com.]

three designed power dividers. It is seen from Table II that the required length of the proposed Wilkinson power divider is close to that of a conventional one at the minimum frequency. Also, it is seen from Table II and Figures 2-5 that as the desired frequencies move farther from the fundamental frequency and its odd harmonics, the required length is increased, the variations of the normalized width function are increased and the input and output return losses as well as the output isolation are decreased.

The designed power divider for frequencies [1, 2.8, 4.5] $\mathrm{GHz}$ is fabricated on a substrate with $\varepsilon_{\mathrm{r}}=2.2$ and $h=20$

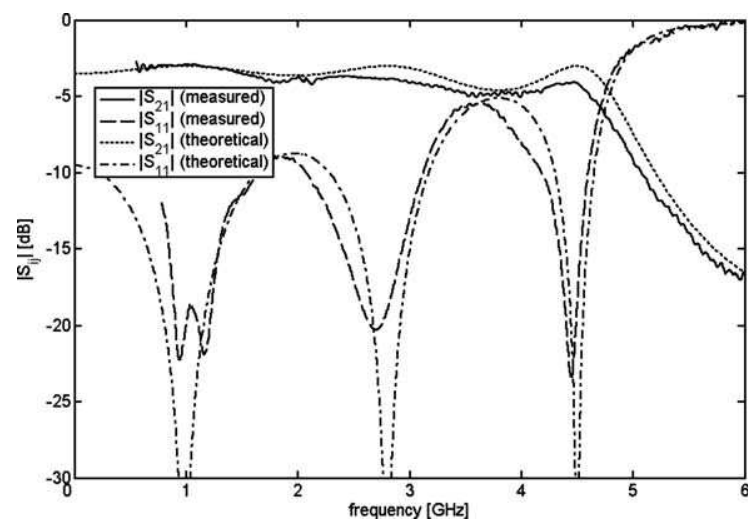

Figure 7 The measured and theoretical parameters $\left|S_{11}\right|$ and $\left|S_{21}\right|$ of the fabricated power divider. 


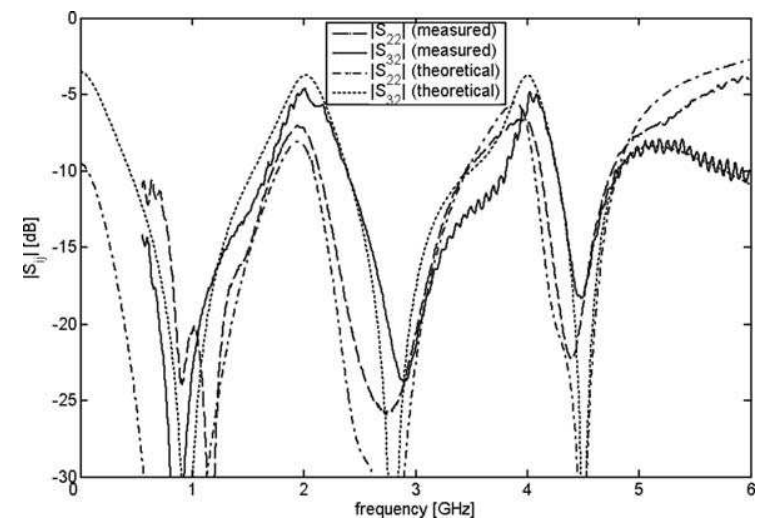

Figure 8 The measured and theoretical parameters $\left|S_{22}\right|$ and $\left|S_{32}\right|$ of the fabricated power divider.

mil $=508 \mu \mathrm{m}(\mathrm{RT} /$ Duroid 5880 from Rogers) as shown in Figure 6. Figures 7 and 8 compare the measured and theoretical amplitude of the scattering parameters of the fabricated power divider with each other. It is seen from Figures 7 and 8 that the agreement between theoretical and measurement results is good. The insertion loss of the fabricated power divider is $0.1,0.7$, and $1.0 \mathrm{~dB}$ at frequencies $1.0,2.8$, and $4.5 \mathrm{GHz}$, which is due to the losses of substrate, conducting strips and connectors as well as radiation. Also, the minimum of the input and output return losses and the output isolation are $18.5,20$, and $18 \mathrm{~dB}$ at frequencies $1.0,2.8$, and $4.5 \mathrm{GHz}$, respectively. Taking into account the weak validation of the quasi-TEM approximation at wide strips and also the proximity of two lines at the connection point could yield better practical results.

\section{CONCLUSIONS}

Nonuniform Wilkinson power dividers were proposed to operate at two or several desired frequencies. The proposed structure contains two MNTLs instead of two uniform ones. The strip width of MNTLs is considered vari- able and is written as a truncated Fourier series. Three nonuniform power dividers are designed and one of them operating at frequencies $1.0,2.8$, and $4.5 \mathrm{GHz}$ is fabricated and measured. The measured results of the fabricated diplexer have a good agreement with the theoretical results. The insertion loss of the fabricated power divider was $0.1,0.7$, and $1.0 \mathrm{~dB}$ at frequencies $1.0,2.8$, and 4.5 $\mathrm{GHz}$. Also, the minimum of the input and output return losses and the output isolation are 18.5, 20, and $18 \mathrm{~dB}$ at frequencies 1.0, 2.8 and $4.5 \mathrm{GHz}$, respectively.

\section{REFERENCES}

1. D.M. Pozar, Microwave Engineering, Addison-Wesley, New York, USA, 1990.

2. E.J. Wilkinson, An N-way hybrid power divider, IRE Trans Microwave Theory Tech MTT-8 (1960), 116-118.

3. S. Srisathit, M. Chongcheawchamnan, and A. Worapishet, Design and realization of dual-band $3 \mathrm{~dB}$ power divider based on two-section transmission-line topology, Electron Lett 39 (2003), 723-724.

4. L. Wu, Z. Sun, H. Yilmaz, and M. Berroth, A dual-frequency Wilkinson power divider, IEEE Trans Microwave Theory Tech 54 (2006), 278-284.

5. K.M. Cheng and F.-L. Wong, A new Wilkinson power divider design for dual band application, IEEE Microwave Wirel Compon Lett 17 (2007), 664-666.

6. N. Dib and M. Khodier, Design and optimization of multiband wilkinson power divider, Int J RF Microwave ComputAided Eng 18 (2008), 14-20.

7. I.-H. Lin, M. De Vincentis, C. Caloz, and T. Itoh, Arbitrary dual-band components using composite right/left-handed transmission lines, IEEE Trans Microwave Theory Tech 52 (2004), $1142-1149$

8. M. Khalaj-Amirhosseini, Analysis of coupled nonuniform transmission lines using short exponential or linear sections, J Electromagn Waves Appl 21 (2007), 299-312.

9. M. Khalaj-Amirhosseini, Using linear sections instead of uniform ones to analyze the coupled nonuniform transmission lines, Int J RF Microwave Comput-Aided Eng 19 (2009), 75-79.

\section{BIOGRAPHIES}

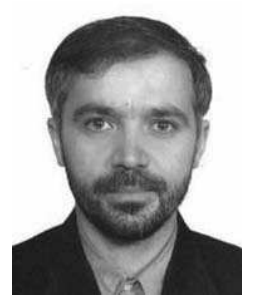

Mohammad Khalaj Amirhosseini was born in Tehran, Iran in 1969. He received his B.Sc, M.Sc and Ph.D. degrees from Iran University of Science and Technology (IUST) in 1992, 1994 and 1998 respectively, all in Electrical Engineering. He is currently an Associate Professor at College of Electrical Engineering of IUST. His scientific fields of interest are electromagnetic direct and inverse problems including microwaves, antennas and electromagnetic compatibility.

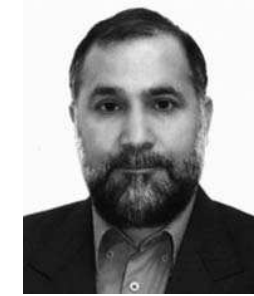

Prof. Dr. Mahmoud Moghavvemi was born in Tehran, Islamic republic of Iran in 1969. He obtained his B.Sc in Electrical Engineering from the State University of New York, MSc from University of Bridgeport and $\mathrm{PhD}$ from the University of Malaya. $\mathrm{He}$ is the Director of Centre for Research in Applied Electronics (CRAE). He is an invited member of New York Academy of sciences and member of who is who in the world since 2007. His current research interests are: electronic circuit design; application toward sensory interface electronics in industrial, commercial, scientific, transportation, and biomedical systems. 


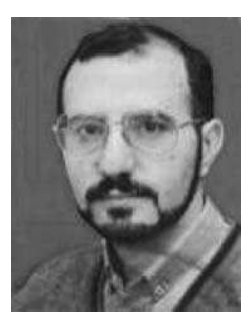

Hossein Ameri was born in Ardestan, Iran. He received the B.S.E.E. and M.S.E.E degree from the University of Tehran, and is currently working toward the Ph.D. in electrical engineering at the University of Malaya(UM) at Malaysia. His research interests include microwave, millimeter-wave, passive and active components, sub-systems and systems. Such as Synthesizer, power amplifier, high power combiner, antennas, digital microwave, mm-wave Links, Terahertz synthesizer and antennas. 